\title{
BMJ Open Primary care for patients with respiratory tract infection before and early on in the COVID-19 pandemic: an observational study in 16 European countries
}

\begin{abstract}
Alike W van der Velden (D) , ${ }^{1}$ Eva A Bax, ${ }^{1}$ Emily Bongard (D) , ${ }^{2}$ Rune Munck Aabenhus, ${ }^{3}$ Marilena Anastasaki, ${ }^{4}$ Sibyl Anthierens, ${ }^{5}$ Anca Balan, ${ }^{6}$ Femke Böhmer, ${ }^{7}$ Pascale Bruno, ${ }^{8}$ Slawomir Chlabicz, ${ }^{9}$ Samuel Coenen (D) , ${ }^{5}$ Annelies Colliers (D) , ${ }^{5}$ Susanne Emmerich, ${ }^{10}$ Ana Garcia-Sangenis (D) ,11 Hrachuhi Ghazaryan, ${ }^{12}$ Sanne R van der Linde, ${ }^{1}$ Lile Malania, ${ }^{13}$ József Pauer, ${ }^{14}$ Angela Tomacinschii, ${ }^{15}$ Sarah Tonkin-Crine (1) , ${ }^{2}$ Akke Vellinga (I) , ${ }^{16}$ Ihor Zastavnyy, ${ }^{17}$ Theo Verheij, ${ }^{1}$ Herman Goossens, ${ }^{18}$ Christopher C Butler (D) ${ }^{2}$
\end{abstract}

To cite: van der Velden AW, Bax EA, Bongard $\mathrm{E}$, et al. Primary care for patients with respiratory tract infection before and early on in the COVID-19 pandemic: an observational study in 16 European countries. BMJ Open 2021;11:e49257. doi:10.1136/ bmjopen-2021-049257

- Prepublication history and additional supplemental material for this paper are available online. To view these files, please visit the journal online (http://dx.doi.org/10.1136/ bmjopen-2021-049257).

Received 11 February 2021 Accepted 07 July 2021

\section{Check for updates}

(C) Author(s) (or their employer(s)) 2021. Re-use permitted under CC BY-NC. No commercial re-use. See rights and permissions. Published by BMJ.

For numbered affiliations see end of article.

\section{Correspondence to} Dr Alike W van der Velden; a.w.vandervelden@umcutrecht. $\mathrm{nl}$

\section{ABSTRACT}

Objective To describe primary health care (consultation characteristics and management) for patients contacting their general practitioner (GP) with a respiratory tract infection (RTI) early on in the COVID-19 pandemic in contrasting European countries, with comparison to prepandemic findings.

Setting Primary care in 16 countries (79 practices), when no routine SARS-CoV-2 testing was generally available. Design and participants Before $(n=4376)$ and early in the pandemic $(n=3301)$, patients with RTI symptoms were registered in this prospective audit study.

Outcome measures Consultation characteristics (type of contact and use of PPE) and management characteristics (clinical assessments, diagnostic testing, prescribing, advice and referral) were registered. Differences in these characteristics between countries and between pandemic and prepandemic care are described.

Results Care for patients with RTIs rapidly switched to telephone/video consultations (10\% in Armenia, $91 \%$ in Denmark), and when consultations were face-to-face, GPs used PPE during $97 \%$ (95\% Cl $96 \%$ to $98 \%$ ) of contacts. Laboratory testing for SARS-CoV-2 in primary care patients with RTIs was rapidly implemented in Denmark (59\%) and Germany (31\%), while overall testing for C reactive protein decreased. The proportion of patients prescribed antibiotics varied considerably between countries (3\% in Belgium, $48 \%$ in UK) and was lower during the pandemic compared with the months before, except for Greece, Poland and UK. GPs provided frequent and varied COVID-related advice and more frequently scheduled a follow-up contact ( $50 \%, 95 \% \mathrm{Cl} 48 \%$ to $52 \%$ ). GPs reported a slightly higher degree of confidence in the likely effectiveness of their management in face-to-face ( $73 \%$ (very) confident, $95 \% \mathrm{Cl} 71 \%$ to $76 \%$ ) than in virtual consultations (69\%, 95\% Cl $67 \%$ to $71 \%)$.

Conclusions Despite between-country variation in consultation characteristics, access to SARS-CoV-2 laboratory testing and medication prescribing, GPS reported a high degree of confidence in managing their
Strength and limitations of this study

The operational infrastructure of this point prevalence audit survey in 16 European countries enabled data collection on patient consultations for respiratory tract infections early on in the first wave of the COVID-19 pandemic.

- This prospective audit enabled an exploratory between-country comparison in care delivery early on in the COVID-19 pandemic, as well as direct comparison to prepandemic care.

- The prospective registration reduced risk of 'information bias'.

- A limited number of practices per country participated in the registration audit.

- Data from qualitative studies could further contextualise our findings.

patients with RTIs in the emerging pandemic. Insight in the highly variable pandemic responses, as measured in this multicountry audit, can aid in fine-tuning national action and in coordinating a pan-European response during future pandemic threats.

\section{INTRODUCTION}

The COVID-19 pandemic has brought dramatic changes in the delivery of primary healthcare, especially for patients with respiratory tract infections. ${ }^{1-4}$ There was an urgent imperative to minimise risk of transmission of viral infections by reducing face-to-face consultations and to identify, monitor and treat those patients developing an adverse illness course. ${ }^{235}$ However, the management of patients with respiratory tract infections (RTIs), and especially those suspected of having COVID-19, was impeded by the lack of 
evidence regarding diagnosis and treatment of COVID$19 .{ }^{67}$ Furthermore, poor availability of personal protective equipment (PPE) and laboratory testing capacity for SARS-CoV-2, ${ }^{2}$ and differences in governmental policies for containing the pandemic hampered a consistent and uniform management of suspected COVID-19 in primary care across Europe. Therefore, care provision and workflows had to be responsive to many rapidly changing circumstances.

Research during the initial phase of the pandemic was largely secondary care focused, whereas most patients were managed in the community. Primary care has an essential role in any emergency response, as being the first point of call for patients and the first line of defence for the healthcare system. ${ }^{13}$ Therefore, containing the spread of pandemic pathogens, while also providing safe and effective care will remain a critical task for European primary care.

The provision of primary care, as well as integration in national healthcare systems, varies enormously between European countries. Benchmarking primary care provision in Europe in the initial phase of the pandemic, especially for patients with RTIs, may help in understanding problems that were encountered, provide insight in variation of care and inform future responses, thus potentially harmonising and improving outpatient care in Europe during future pandemic threats.

Therefore, our objective was to describe consultation characteristics (virtual or face-to-face contact and general practitioner's (GP) use of PPE) and management (clinical assessments, diagnostic testing, medication prescribing and provided advice) of patients presenting with RTI symptoms early on in the COVID-19 pandemic in 16 European countries. Second, we aimed to compare these characteristics between countries and with findings from a similar audit conducted just before the pandemic.

\section{METHODS}

We performed a prospective point prevalence audit survey (PPAS) of consultation and management characteristics of patients with RTIs in contrasting EU and non-EU European countries (observational exploratory study). It initially ran January and February 2020 (PPAS1) but was reinitiated in all participating countries at the beginning of the initial European COVID-19 wave (March 2020) to capture changes in healthcare delivery, and continued in April and May 2020 (PPAS2). GPs anonymously registered patients who contacted their practice about RTI symptoms. The audit aimed to describe overall patient care. As no personally identifiable information was collected, patients were not asked to provide informed consent.

\section{Setting}

We included purposively selected practices from primary care networks in high-income, upper-middle-income and lower-middle-income countries: Armenia $(n=1$, large paediatric primary care clinic), Belgium $(n=6)$,
Germany $(n=2)$, Denmark $(n=4)$, Spain $(n=5)$, France $(n=10)$, Georgia $(n=5)$, Greece $(n=6)$, Hungary $(n=5)$, Ireland $(n=5)$, Moldova $(n=4)$, the Netherlands $(n=8)$, Poland $(n=6)$, Romania $(n=4)$, Ukraine $(n=4)$ and UK $(n=4)$. The same GPs (in the same practices and with the same patient populations) participated in both phases. National networks were asked to register consultations until they reached the targets of 200-300 in PPAS1 and approximately 200 in PPAS2. Specific focus was on sequentially registering all eligible patients to prevent selection bias. GPs were reimbursed $€ 5-€ 10$ per registered consultation.

\section{Patient and public involvement}

This study was set up rapidly, and due to the timelines involved, it would have been difficult to involve patients and the public. The set-up of the registration form was discussed among researchers from most participating counties.

\section{Eligibility criteria}

In PPAS1, GPs were asked to sequentially register consulting patients of all ages with either sore throat (symptom duration $<14$ days) and/or cough (symptom duration $<28$ days) and to exclude patients with only nasal or ear symptoms. In PPAS2, early on in the pandemic, additionally, patients with coryza and otherwise suspected of having COVID-19 were eligible for registration. Otherwise suspected of COVID-19 refers to patients without signs of an RTI (yet), for whom the GP suspected COVID19. The case report form (CRF) was used in PPAS2 is shown in online supplemental appendix 1.

\section{Data}

Data were entered directly into an online data capture system, Research Online, or could be entered later from paper forms. PPAS1 focused on GPs' management (clinical assessments, diagnostic testing, medication prescribing, advice provided and referral). PPAS2 also included these management variables and was extended with COVID-19-specific items, including use of PPE and additional patient and family advice (CRF in online supplemental appendix 1). Furthermore, GPs rated their level of confidence in the validity of the advice and/or treatment they provided during each contact using a 5-point Likert scale.

\section{Analyses}

To enable comparison between the two audits, registrations from patients with sore throat and/or cough symptoms were selected for the analysis, as these were common to both audits. Additionally, patients with suspected SARS-CoV-2 aetiology (CRF item 10.1) and/or an initial diagnosis of COVID-19 (item 11), but without registered sore throat and/or cough were included (this group in PPAS2 comprised 144 patients, 4.7\%). Frequency data with $95 \%$ CIs (//epitools.ausvet.com.au/ciproportion, Wilson method) were calculated for accumulated data of both PPAS phases, as well as for PPAS2 data in figure 1 
Antibiotics

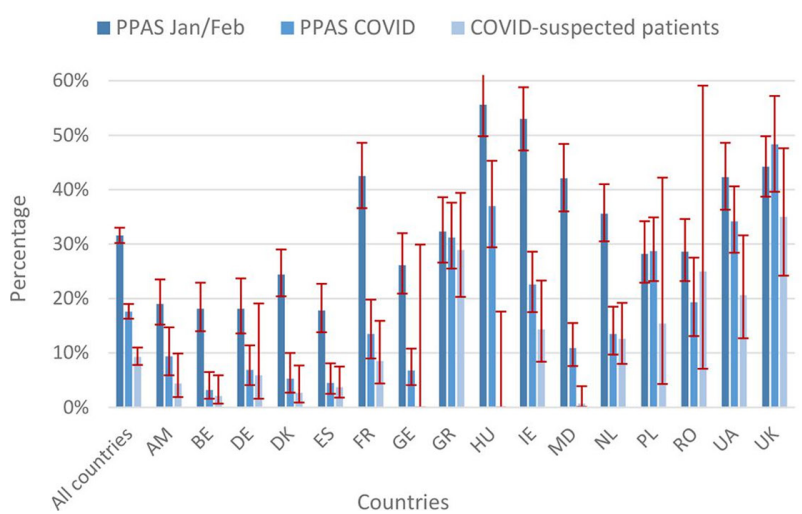

Antivirals

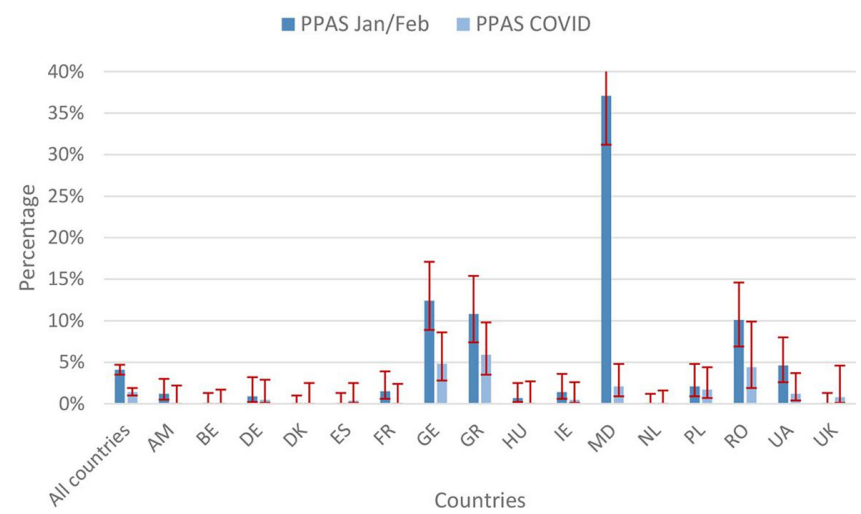

Figure 1 Antibiotic and antiviral prescribing before and early on in the pandemic. The proportions of patients being prescribed antibiotics and antivirals are shown for all countries and per country for patients registered in the first phase and early on in the pandemic. Antibiotic prescribing is also specifically shown for patients suspected of having COVID-19. 95\% Cls are added with bars. Note that the numbers of patients suspected of having COVID-19 vary substantially between countries and can be low (table 1). PPAS, point prevalence audit survey.

and online supplemental appendices. Missing data, less than $1 \%$ per variable, were not corrected for.

Various exploratory comparisons were done:

1. Consultation and management variables from PPAS2 were calculated by country (presented in the online supplemental appendices) enabling between-country comparisons. Notable between-country differences were identified by the core team and discussed with the national network leads and GPs to better understand these differences and as a face validity check.

2. Within PPAS2, management variables were compared between patients consulting face-to-face or virtually.

3. Within PPAS2, management variables were analysed separately for patients suspected of having COVID-19 (suspected aetiology SARS-CoV-2 and/or working diagnosis COVID-19).

4. Where possible data were compared between the two PPAS phases.

\section{RESULTS}

In PPAS1, 4376 consultations were registered (221-381 per country). From 3301 consultations in PPAS2, 3063 (114-238 per country) captured management of patients with sore throat, cough and/or suspected of having COVID-19; the remaining were from patients with only coryza or allergic symptoms. The proportion of patients suspected of having COVID-19 varied markedly between countries, overall $43 \%$ (95\% CI $41 \%$ to $44 \%$ ), ranging from $4 \%$ in Georgia to $84 \%$ in Spain (table 1).

\section{Consultations for RTI symptoms}

Early on in the pandemic, many countries rapidly transformed from face-to-face to virtual consultations (table 2). Overall, over $50 \%$ of consultations were by telephone and $8 \%$ by video connection. In Belgium, Denmark, Ireland, Moldova, Netherlands, Romania and UK, over $70 \%$ of consultations were by telephone/video (online supplemental appendix 2). Possible reasons for a comparatively higher proportion of face-to-face consultations in Armenia and Georgia (non-overlapping 95\% CIs with many other countries) are described in online supplemental appendix 3. In $97 \%$ of face-to-face contacts, GPs reported using PPE, most often face/nose/mouth protection $(96 \%)$, and also gloves $(67 \%)$, safety glasses $(57 \%)$ and/or an apron (52\%). There was marked variation between countries with lower use in Denmark (46\% face/ nose/mouth protection and gloves, no apron and safety glasses), France (21\% gloves) and Germany ( $<2 \%$ apron, safety glasses and gloves; online supplemental appendix 2; note the non-overlapping 95\% CIs). Possible reported reasons were that use of PPE was up to the discretion of GPs (Denmark) and that strict hand hygiene was initially recommended instead of using gloves (France, online supplemental appendix 3). Early on in the pandemic, oxygen saturation was measured more often $(68 \%, 95 \%$ CI $66 \%$ to $71 \%$ ) compared with the prepandemic situation (47\%, 95\% CI $46 \%$ to $49 \%)$. Some countries fed back that oximetry is not part of their guidelines and that very few practices had this device. In both audit phases, a similar proportion of $28 \%$ of patients underwent additional diagnostic testing, with laboratory SARS-CoV-2 testing $(14 \%)$ and more chest X-rays $(8.9 \%)$ requested early on in the pandemic, but fewer CRP $(6.6 \%)$ and white blood cell testing $(7.4 \%)$. In Belgium, Ireland and Netherlands, fewer than $10 \%$ of patients underwent diagnostic testing, while in Denmark and Moldova, tests were done or ordered for over $60 \%$ of patients (non-overlapping 95\% CIs), largely due to the high proportion being tested for SARS-CoV-2. Chest X-rays were done in over 20\% of patients in Greece and Spain, and none in Netherlands, Belgium, Germany and Ireland (non-overlapping 95\% CIs, online supplemental appendix 2).

\section{Prescribed medication}

Antibiotics were prescribed to a substantially lower proportion of patients early on in the pandemic $(17.6 \%$, 
Table 1 Participating countries with numbers of registered patients in the prepandemic phase (PPAS1) and early on in the pandemic (PPAS2), with the \% male, mean age and numbers of patients suspected of having COVID-19 in PPAS2

\begin{tabular}{|c|c|c|c|c|c|}
\hline Country & PPAS1 & PPAS2 & $\%$ Male & Age (mean) & $\begin{array}{l}\text { Patients suspected of having } \\
\text { COVID-19 }\end{array}$ \\
\hline All countries & 4376 & 3063 & 43.7 & 39 & $1304(42.6 \%, 41 \%$ to $44 \%)$ \\
\hline Armenia & 337 & 170 & 51.7 & 6 & $114(67.1 \%, 60 \%$ to $74 \%)$ \\
\hline Belgium & 288 & 216 & 42.7 & 39 & $146(67.6 \%, 61 \%$ to $73 \%)$ \\
\hline Germany & 221 & 189 & 43.2 & 42 & $34(18.0 \%, 13 \%$ to $24 \%)$ \\
\hline Denmark & 381 & 152 & 39.8 & 38 & $110(72.4 \%, 65 \%$ to $79 \%)$ \\
\hline Spain & 286 & 223 & 34.5 & 47 & $188(84.3 \%, 79 \%$ to $88 \%)$ \\
\hline France & 259 & 155 & 49.4 & 46 & $94(60.6 \%, 53 \%$ to $68 \%)$ \\
\hline Georgia & 234 & 222 & 40 & 35 & $9(4.1 \%, 2 \%$ to $8 \%)$ \\
\hline Greece & 232 & 221 & 45.4 & 48 & $83(37.6 \%, 31 \%$ to $44 \%)$ \\
\hline Hungary & 284 & 138 & 50.7 & 46 & $18(13.0 \%, 8 \%$ to $20 \%)$ \\
\hline Ireland & 281 & 217 & 42.5 & 40 & $84(38.7 \%, 32 \%$ to $45 \%)$ \\
\hline Moldova & 240 & 238 & 45.2 & 40 & $140(58.8 \%, 52 \%$ to $65 \%)$ \\
\hline The Netherlands & 312 & 230 & 42.1 & 51 & $135(58.7 \%, 52 \%$ to $65 \%)$ \\
\hline Poland & 241 & 230 & 48.3 & 32 & 13 (5.7\%; 3\% to $9 \%)$ \\
\hline Romania & 238 & 114 & 48 & 27 & $8(7.0 \%, 4 \%$ to $13 \%)$ \\
\hline Ukraine & 241 & 228 & 42.4 & 38 & $68(29.8 \%, 24 \%$ to $36 \%)$ \\
\hline UK & 301 & 120 & 38.6 & 42 & $60(50.0 \%, 41 \%$ to $59 \%)$ \\
\hline
\end{tabular}

Absolute numbers and percentages with $95 \%$ Cls between brackets.

95\% CI $16.3 \%$ to $19 \%)$ as compared with before $(31.6 \%$, 95\% CI $30.2 \%$ to $33 \%$ ), and to an even lower proportion of patients when COVID-19 was suspected (9.3\%, 95\% CI $7.8 \%$ to $11 \%$; figure 1). However, GPs in Greece, Poland, Romania and UK continued to prescribe antibiotics in similar proportions of patients as before the pandemic. Reported reasons include that in Romania, GPs were inclined to advise patients to complete their over-the-counter-purchased antibiotic treatment, and for the UK that antibiotics were considered beneficial for COVID-19 in the first weeks of the pandemic (online supplemental appendix 3). Antibiotic prescribing was also analysed separately for face-to-face and phone/video consultations, showing higher prescribing proportions during face-to-face consultations (table 3 ), which was the case in most countries (online supplemental appendix 4). Proportions of patients receiving antivirals, mainly in Georgia, Greece, Moldova and Romania, decreased early on in the pandemic, overall from $4.1 \%(95 \%$ CI $3.5 \%$ to $4.7 \%$ ) to $1.4 \%$ (95\% CI $1 \%$ to $1.9 \%$ ), also when COVID-19 was suspected (figure 1). Finally, prescription of inhaled medication decreased from $14.9 \%$ (95\% CI

Table 2 Consultation characteristics, use of PPE and measurements during face-to-face consultations, and diagnostic testing and referral for all contacts

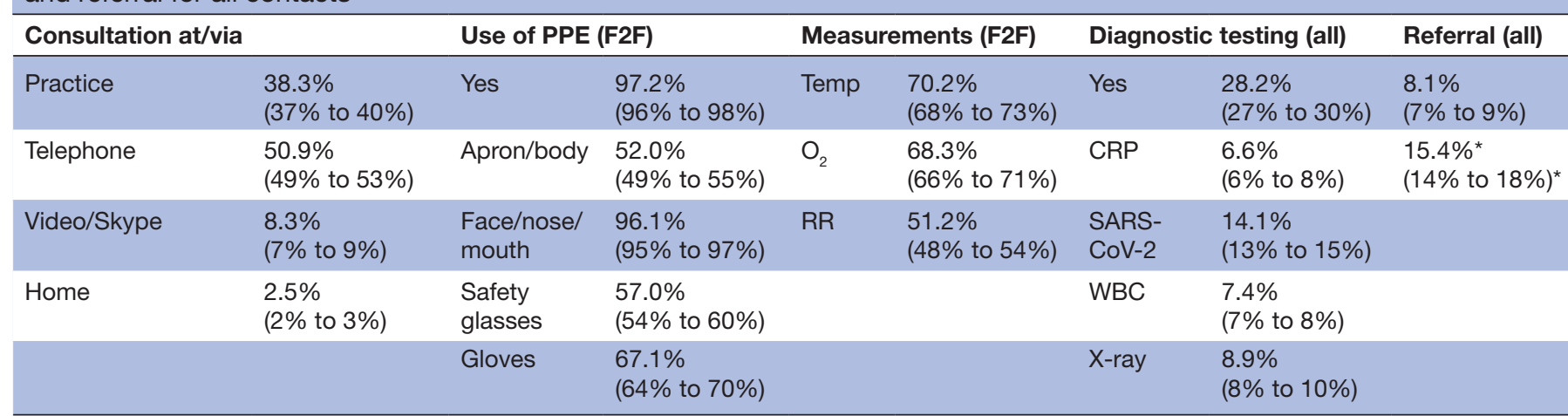

Mean percentages with 95\% Cls are shown.

Data for individual countries are shown in online supplemental appendix 2.

${ }^{*}$ Patients suspected of having COVID-19.

CRP, C reactive protein; F2F, face to face; PPE, personal protective equipment; RR, respiratory rate; WBC, white blood cell count. 
Table 3 Antibiotic prescribing, hospital referral and confidence with management, split for practice/home and phone/video contacts, and specifically for patients suspected of having COVID-19

\begin{tabular}{llll}
\hline & Antibiotic & Referral & Confidence advice/treatment \\
\hline All patients (F2F) & $23.0 \%(21 \%$ to $26 \%)$ & $10 \%(9 \%$ to $12 \%)$ & $12.6 \%-60.6 \%-24.4 \%-2.0 \%-0.5 \%$ \\
COVID-19 suspected (F2F) & $11.6 \%(10 \%$ to $14 \%)$ & $21.2 \%(19 \%$ to $24 \%)$ & $12.5 \%-52.3 \%-30.4 \%-3.4 \%-1.4 \%$ \\
All patients (P/V) & $13.9 \%(12 \%$ to $16 \%)$ & $6.8 \%(6 \%$ to $8 \%)$ & $9.0 \%-60.0 \%-27.9 \%-2.9 \%-0.2 \%$ \\
COVID-19 suspected (P/N) & $8.2 \%(7 \%$ to $10 \%)$ & $12.7 \%(11 \%$ to $14 \%)$ & $8.0 \%-56.0 \%-31.4 \%-4.3 \%-0.4 \%$ \\
\hline
\end{tabular}

Mean percentages with 95\% Cls are shown.

Data for individual countries are shown in online supplemental appendix 4.

*Very confident-confident-moderately confident-unconfident-very unconfident.

F2F, face to face; P/V, phone/video.

$13.9 \%$ to $16 \%$ ) to $12.3 \%$ of patients $(95 \%$ CI $11.2 \%$ to $13.5 \%$ ) early on in the pandemic.

\section{Referral}

Early on in the pandemic, a higher proportion of patients were referred to hospital, overall in $8 \%$ (95\% CI $7 \%$ to $9 \%$ ) of contacts (table 2), as compared with $3 \%$ (95\% CI $2.5 \%$ to $3.5 \%$ ) before the pandemic. Low referral rates in Hungary and Ireland (non-overlapping 95\% CIs with many other countries) were reported to be caused by the vast majority of patients presenting with mild symptoms (online supplemental appendices 2 and 3). A higher proportion of patients were referred after a face-to-face contact $(10 \%)$ than after a virtual consultation $(6.8 \%$, non-overlapping 95\% CIs; table 3). Overall, $15 \%$ (95\% CI
$13 \%$ to $17 \%$ ) of patients suspected of having COVID-19 were referred for hospital assessment and of referrals in the pandemic, $78 \%$ had a working diagnosis of COVID-19. Online supplemental appendix 4 shows hospital referral by country, split for face-to-face and virtual consultations.

\section{Advice for patients}

GPs reported providing various types of advice to their patients, about symptomatic treatment ( $76 \%$ of contacts), preventive measures $(64 \%)$, like extra handwashing and social distancing, and advice for home isolation $(67 \%$, table 4). The latter was higher when COVID-19 was suspected ( $83 \%$ of contacts, non-overlapping 95\% CIs). About half of the patients also received advice for their family members, which was $70 \%$ when COVID-19 was

Table 4 Advice provided to all patients early on in the pandemic and separately for patients suspected of having COVID-19

\begin{tabular}{|c|c|c|c|}
\hline Advice for home isolation & $\begin{array}{l}67.2 \%(66 \% \text { to } 69 \%) \\
83.2 \%(81 \% \text { to } 85 \%)^{\star}\end{array}$ & & \\
\hline Advice for symptomatic treatment & $\begin{array}{l}75.6 \%(74 \% \text { to } 77 \%) \\
70.4 \%(68 \% \text { to } 73 \%)^{*}\end{array}$ & & \\
\hline A scheduled follow-up visit/call & $\begin{array}{l}49.9 \%(48 \% \text { to } 52 \%) \\
51.5 \%(49 \% \text { to } 54 \%)^{\star}\end{array}$ & & \\
\hline \multirow[t]{2}{*}{ Advice for family members } & $\begin{array}{l}51.9 \%(50 \% \text { to } 54 \%) \\
69.6 \%(68 \% \text { to } 72 \%)^{*}\end{array}$ & Home isolation & $\begin{array}{l}34.0 \%(32 \% \text { to } 36 \%) \\
54.7 \%(52 \% \text { to } 57 \%)^{*}\end{array}$ \\
\hline & & Social distancing & $\begin{array}{l}40.2 \%(39 \% \text { to } 42 \%) \\
53.1 \%(50 \% \text { to } 56 \%)^{*}\end{array}$ \\
\hline \multirow[t]{3}{*}{ Preventive measures for patient } & $\begin{array}{l}64.1 \%(62 \% \text { to } 66 \%) \\
68.6 \%(66 \% \text { to } 71 \%)^{*}\end{array}$ & Extra handwashing & $\begin{array}{l}56.7 \%(55 \% \text { to } 59 \%) \\
62.4 \%(60 \% \text { to } 65 \%)^{*}\end{array}$ \\
\hline & & Sneezing in sleeve & $\begin{array}{l}47.2 \%(46 \% \text { to } 49 \%) \\
48.4 \%(46 \% \text { to } 51 \%)^{\star}\end{array}$ \\
\hline & & Staying in separate room & $\begin{array}{l}27.3 \%(26 \% \text { to } 29 \%) \\
40.6 \%(38 \% \text { to } 43 \%)^{\star}\end{array}$ \\
\hline Where to find reliable information & $\begin{array}{l}20.0 \%(19 \% \text { to } 21 \%) \\
28.0 \%(26 \% \text { to } 31 \%)^{*}\end{array}$ & & \\
\hline
\end{tabular}

Mean percentages with $95 \% \mathrm{Cls}$ are shown.

Data for individual countries are shown in online supplemental appendix 5.

*Patients suspected of having COVID-19. 
suspected. In Armenia, Belgium, Denmark, Poland and UK, GPs seemed to have provided less frequent advice than in the other countries (online supplemental appendix 5; note the $95 \%$ CIs). Reported reasons were that advice on quarantine, social distancing and hygiene were already strongly promoted by the government and considered common knowledge (online supplemental appendix 3). Before the pandemic, a follow-up consultation was scheduled for $9 \%$ (95\% CI $8 \%$ to $10 \%)$ of patients, which was markedly higher early on in the pandemic $(50 \%, 95 \%$ CI $48 \%$ to $52 \%$ ).

\section{Confidence of GPs in the benefit of their treatment and advice}

GPs' confidence in their patient management ('how confident are you that your advice and/or treatment will benefit this patient') was rated only slightly higher for face-to-face consultations (GPs (very) confident in 73\% (95\% CI $71 \%$ to $76 \%$ ) of contacts) than for virtual consultations (GPs (very) confident in 69\% (95\% CI 67\% to $71 \%$ ) of contacts, table 3 ). GPs reported low confidence in over $10 \%$ of contacts in Belgium and Denmark, and specifically for virtual consultations in Armenia (online supplemental appendix 4).

\section{DISCUSSION}

\section{Key findings}

Primary care has been shown to be highly adaptable in meeting the demands of providing patient care under challenging pandemic circumstances. GPs had to manage patients with RTI without knowing whether the aetiology was SARS-CoV-2, or another pathogen. Routine diagnostic testing was not yet implemented and diagnosis was based on clinical view. Primary care dramatically reduced face-to-face contacts and increased consultations by telephone and video. Antibiotic prescribing reduced substantially, but marked differences between countries remained. Other important management issues, such as use of PPE, oxygen saturation and respiratory rate measurements, and diagnostic testing, also varied considerably between countries. Compared with prepandemic care, a higher proportion of patients were referred to secondary care, which probably reflected national guidance to refer patients suspected of having COVID-19 with more severe symptoms to hospital. Proportionally more patients who remained under community care had a follow-up contact scheduled. Despite many uncertainties, lack of guidelines, unprecedented restructuring of, and large between-country differences in care provision, GPs generally reported high confidence in managing their patients with RTI symptoms during the hectic pace of the emerging pandemic.

In contextualising these findings, the timing of the audit - registrations were mainly from the first 2 months of the pandemic - is of relevance. In that phase, estimates of SARS-CoV-2 incidence among patients consulting in primary care with acute RTI-type symptoms were unknown, as rapid (mass) testing was not yet implemented for this patient group. This was shown by the low frequency of laboratory-based testing for SARS-CoV-2; only Denmark and Germany used lab testing for a substantial proportion of symptomatic primary care patients. Therefore, at the point of care, no confirmed COVID-19 diagnosis could usually be made. Moreover, COVID-19 was a new disease and no evidence-based treatment guidance was available, and advice by public health and professional organisations regarding diagnosis, riskfactors, treatment options and referral rapidly changed and was affected by various government measures. In some countries, a COVID-19 diagnosis was based on specific symptoms, such as loss of taste and/or smell, or having had contact with a proven positive case. In other countries, all patients presenting with RTI symptoms were considered as 'COVID-19-suspected'. This is reflected by the high between-country variation in the proportion of patients suspected of having COVID-19 (4\%-84\%). This variation cannot be explained by differences in disease incidences and looking back COVID-19 incidences were overestimated. All data that we captured, therefore, should be considered in the context of uncertain and rapidly changing circumstances, and cannot be related to retrospectively known variables like incidence rates and prevalence for that period.

\section{Strengths and weaknesses}

The main strength was the up and running PPAS infrastructure in 16 European countries. This allowed for (1) the rapid initiation early on in the COVID-19 pandemic when structural testing was not implemented yet, (2) prospective data collection using a standardised instrument, and (3) exploratory comparisons between countries and with prepandemic data. Thereby, we have been able to capture the transition of European primary healthcare in a phase when no rapid (mass) testing for SARS-CoV-2 was implemented, and GPs had to base their treatment and advice on clinical view, and rapidly changing overall and epidemiological information. Findings can be helpful for countries in reflecting on this transition phase and in planning how to better respond to pandemic threats in the future. This study has several limitations too. First, patient registration took place in 1 to 10 primary care practices per country, and therefore may not accurately reflect overall practice at a country level. Second, although all countries started registering early in the first pandemic wave, some reached their target earlier than others, and during the registration period, countries implemented measures and restrictions at different times. Such contextual influences and perceived incidences will have accounted for some of the between-country differences. Lastly, we did not prospectively collect data about possible reasons underlying reported practice. Therefore, we asked the network leads and they in turn their registering GPs for possible explanations for findings. This retrospective reflection may have been influenced by personal experiences and was not analysed using formal qualitative study methods. 


\section{Comparison with other studies}

Literature on the impact of the pandemic on primary care is emerging. It has been described how national primary care systems have adapted and performed to meet the COVID19-induced challenges, starting with the transition to phone/ video consultations. ${ }^{3}{ }^{46-10}$ These general descriptions have, however, not been presented as between-country comparisons thus far, and they have not been based on prospectively collected data. Some country comparisons of responses of primary care opinion leaders have been published. A benchmarking study with primary care leaders in 111 countries highlighted that all nations have room to improve. ${ }^{11}$ A qualitative opinion exercise with 29 countries learnt that primary care continued as the first point of contact to the health system and rapidly separated RTI from other care, but was poorly informed and ill equipped to provide care while protecting staff and patients. ${ }^{2}$ Similar findings resulted from a survey among GPs in the UK, specifically mentioning technical difficulties, financial issues and inadequate provision of PPE. ${ }^{912}$ A commentary on the primary care response in six well-resourced countries highlighted areas where COVID-19 has directly spurred progress (telemedicine and collaboration with public health), as well as exposed latent weaknesses (non-COVID and chronic conditions management) ${ }^{13}$ which was reinforced by interview studies with Flemish GPs. ${ }^{14}$ Such opinions might be supported and/or compared with data from the PPAS2. For example, our study reported abundant use of PPE and when not used, other reasons than initial shortage, or costs were mentioned.

Several studies stress the important advisory role of GPs in disseminating fit-for-purpose information and reinforcing critical public health messages. ${ }^{235}$ Our study has shown that GPs, even in the face of pressures from the emerging COVID-19 pandemic, took informing their patients very seriously and provided a lot of tailored advice. With respect to advice provision, we had to rely on the GPs' registration accuracy, as the study design did not allow us to capture this information from patients.

It has been posed that virtual consultations might limit diagnostic capabilities and lead to more empiric and over-prescribing of antibiotics. ${ }^{15} 16$ In our study, antibiotic prescribing rates reduced in the majority of countries during the pandemic. Total antibiotic prescribing is, however, not only influenced by the proportions of those who consulted and were prescribed antibiotics but also by the numbers of RTI patients that presented to primary care. Presentations might have increased because of wanting to be assessed for possible COVID-19 and COVID-related anxiety. On the other hand, presentations might have reduced because of a lower incidence of RTI due to social distancing, school closure and the advice to avoid attending healthcare facilities. Consequences of the pandemic on presentation and antibiotic prescribing for infectious diseases have recently been reported for the Netherlands. ${ }^{17}$

\section{Implications for clinicians and policy makers}

Our study has shown that European primary care practices reinvented themselves early on in the COVID-19 pandemic by switching to virtual consultations, using PPE, increasing oxygen saturation measurements, and implementing lab-testing for SARS-CoV-2. GPs rapidly changed care provision for patients with RTI symptoms, and despite many uncertainties reported high confidence about the likely effectiveness of the treatment and/or advice they gave to their patients. Despite initial perceptions about potential benefit from macrolide antibiotics for patients with COVID-19, ${ }^{18}$ GPs generally did not prescribe antibiotics for those patients. Multicountry, realtime audits, such as our PPAS, could serve as a stimulus for adjusting management strategies during next COVID-19 or new pandemic waves, and thereby aid in coordinating a unified, pan-European pandemic response.

\section{Author affiliations}

${ }^{1}$ Julius Center for Health Sciences and Primary Care, UMC Utrecht, Utrecht, The Netherlands

${ }^{2}$ Nuffield Department of Primary Care Health Sciences, University of Oxford, Oxford, UK

${ }^{3}$ Institute for Public Health, University of Copenhagen, Copenhagen, Denmark ${ }^{4}$ Clinic of Social and Family Medicine, University of Crete, Heraklion, Greece ${ }^{5}$ Family Medicine and Population Health, Universiteit Antwerpen, Antwerpen, Belgium

${ }^{6}$ Balan Medfam SRL, Cluj Napoca, Romania

${ }^{7}$ Institute of General Practice, Rostock University Medical Center, Rostock, Germany ${ }^{8}$ Département de Santé Publique, Centre Hospitalier Universitaire de Nice, Nice, France

${ }^{9}$ Department of Family Medicine Medical, University of Bialystok, Bialystok, Poland

${ }^{10}$ Abbott Rapid Diagnostics Germany GmbH, Cologne, Germany

${ }^{11}$ Medicines Research Unit, Institut Universitari d'Investigació en Atenció Primària Jordi Gol (IDIAP Jordi Gol), Barcelona, Spain

${ }^{12}$ General Pediatrics, Wigmore Clinic Medical Center Yerevan, Yerevan, Armenia

${ }^{13}$ National Center for Disease Control and Public Health, Tbilisi, Georgia

${ }^{14}$ Drug Research Centre LLC, Balatonfüred, Hungary

${ }^{15}$ University Clinic of Primary Medical Assistance, State University of Medicine 'N.

Testemițanu', Chişinău, the Republic of Moldova

${ }^{16}$ School of Medicine, NUI Galway, Galway, Ireland

${ }^{17} \mathrm{NGO}$ Academy of Family Medicine of Ukraine, Lviv, Ukraine

${ }^{18}$ Medical Microbiology, Vaccine and Infectious Diseases Institute (VAXINFECTIO), University of Antwerp, Antwerp, Belgium

\section{Twitter Christopher C Butler @ChrisColButler}

Acknowledgements We would like to express our gratitude to the 16 primary care research networks, their general practitioners and teams for collaborating and registering in the point prevalence audit surveys (PPASs). Roxanne Schaakxs is acknowledged for building the online data capture tool and data management and Adam Zerda for valuable input. We are grateful to Christos Lionis, Pia Touboul, Réka Pauer, Bernadett Kovács, Karen Farrell, Michelle van Willige, Tycho van der Linde, Carl Llor, Ana Moragas, Alex Prats, Paata Imnadze, Ketevan Sidamonidze, Ekaterine Khmaladze, Ryan Arner, Vladyslav Odrynskyi, Irini Vasilaki, Myron Galenianos, Attila Altiner, Barbara Pytel-Krolczuk, Tiphanie Bouchez, David Darmon, Lilit Ghazaryan and Kristina Gyurjyan for their support in initiating, setting up and/or supervising the PPAS in their countries.

Contributors This study was designed and conceived by AWvdV, CCB, HGo, TV, EB, SE and SCo. ST-C and SA provided input to the case report form. RMA, $A C, A B, F B, P B, A G-S, H G h, M A, L M, J P, S C h, A T, A V, I Z, A W v d V$ and EB were responsible for implementing the point prevalence audit survey in their countries (permissions/waivers from ethics committees, managing practices, checking and entering data). AWvdV, EAB and SRvdL conducted the data analyses. AWvdV wrote the first draft of this manuscript and acted as guarantor. CCB and TV critically revised the manuscript. All authors read and approved the final version of the manuscript.

Funding This work was supported by the Innovative Medicine Initiative 2 Joint Undertaking (grant number 820755, VALUE-Dx) and by the Horizon 2020 research and innovation programme (grant number 101003589, RECOVER). 
Competing interests AWvdV, CCB, TV, ST-K, SA, EB and HGo received unrestricted funding for studies from the European Commission (IMI2 and H2020). SE is an employee of Abbott Rapid Diagnostics Germany.

Patient consent for publication Not required.

Ethics approval Regulatory approvals or waivers were sought in each individual country. The following Ethics Committees were consulted: Medical Ethics Committee of University Medical Center Utrecht-Netherlands, Ethics Committee of Antwerp University Hospital-Belgium, Health Research Authority London-UK, Bioethical Committee of the Medical University of Bialystok-Poland, The Danish National Committee of Health Research Ethics-Capitol Region-Denmark, Institutional Review Board of the National Center for Disease Control and Public Health-Tbilisi-Georgia, Research Ethics Committee of the Irish College of General Practitioners-Ireland, Ethical Board of College of Physicians Cluj Napoca-Romania, Medical Research Council Scientific Research Ethics Committee-Hungary, Ethical Board of Academy of Family Medicine of Ukraine-Ukraine, Rostock University Medical Centre Ethics Committee-Germany, Ethics Committee CEI IDIAPJGolBarcelona-Spain, Clinical Research and Innovation Delegation of the University Hospital Nice-France, Ethical Committee at Yerevan State Medical UniversityArmenia, National Committee for Ethical Expertise Ministry of Heath, Labor and Social Protection of the Republic of Moldova and Bioethics Committee University of Crete-Greece.

Provenance and peer review Not commissioned; externally peer reviewed.

Data availability statement Data are available upon reasonable request. Additional to the items reported here, outcomes for all items in the Case Report Form (online supplemental appendix 1 ) are available for all countries, or per individual country, upon request, explaining research question and methods, from the first author (AWvdV) who will seek agreement from the core research team.

Supplemental material This content has been supplied by the author(s). It has not been vetted by BMJ Publishing Group Limited (BMJ) and may not have been peer-reviewed. Any opinions or recommendations discussed are solely those of the author(s) and are not endorsed by BMJ. BMJ disclaims all liability and responsibility arising from any reliance placed on the content. Where the content includes any translated material, BMJ does not warrant the accuracy and reliability of the translations (including but not limited to local regulations, clinical guidelines, terminology, drug names and drug dosages), and is not responsible for any error and/or omissions arising from translation and adaptation or otherwise.

Open access This is an open access article distributed in accordance with the Creative Commons Attribution Non Commercial (CC BY-NC 4.0) license, which permits others to distribute, remix, adapt, build upon this work non-commercially, and license their derivative works on different terms, provided the original work is properly cited, appropriate credit is given, any changes made indicated, and the use is non-commercial. See: http://creativecommons.org/licenses/by-nc/4.0/.

\section{ORCID iDs}

Alike W van der Velden http://orcid.org/0000-0002-9443-2837

Emily Bongard http://orcid.org/0000-0001-5957-6280

Samuel Coenen http://orcid.org/0000-0002-1238-8052

Annelies Colliers http://orcid.org/0000-0003-4960-2355

Ana Garcia-Sangenis http://orcid.org/0000-0002-6689-6466

Sarah Tonkin-Crine http://orcid.org/0000-0003-4470-1151

Akke Vellinga http://orcid.org/0000-0002-6583-4300

Christopher C Butler http://orcid.org/0000-0002-0102-3453

\section{REFERENCES}

1 Dunlop C, Howe A, Li D, et al. The coronavirus outbreak: the central role of primary care in emergency preparedness and response. BJGP Open 2020;4. doi:10.3399/bjgpopen20X101041. [Epub ahead of print: 01 May 2020].

2 Rawaf S, Allen LN, Stigler FL, et al. Lessons on the COVID-19 pandemic, for and by primary care professionals worldwide. Eur $J$ Gen Pract 2020;26:129-33.

3 Krist AH, DeVoe JE, Cheng A, et al. Redesigning primary care to address the COVID-19 pandemic in the midst of the pandemic. Ann Fam Med 2020;18:349-54.

4 Joy M, McGagh D, Jones N, et al. Reorganisation of primary care for older adults during COVID-19: a cross-sectional database study in the UK. Br J Gen Pract 2020;70:e540-e547:e540-7.

5 Green K. How GPs can contribute to the challenge of covid-19. BMJ 2020;369:m1829.

6 de Sutter A, Llor C, Maier M, et al. Family medicine in times of 'COVID-19': A generalists' voice. Eur J Gen Pract 2020;26:58-60.

7 Kakodkar P, Kaka N, Baig MN. A comprehensive literature review on the clinical presentation, and management of the pandemic coronavirus disease 2019 (COVID-19). Cureus 2020;12:e7560.

8 Allen LN, Dambha-Miller H. COVID-19 and international primary care systems: rebuilding a stronger primary care. BJGP Open 2020;4. doi:10.3399/bjgpopen20X101130. [Epub ahead of print: 27 Oct 2020].

9 Sharma SC, Sharma S, Thakker A, et al. Revolution in UK general practice due to COVID-19 pandemic: a cross-sectional survey. Cureus 2020;12:e9573.

10 Schers H, van Weel C, van Boven K. The COVID-19 pandemic in the Netherlands: impact on primary care. COVID-19: Annals of family medicine. Available: https://deepblue.lib.umich.edu/bitstream / handle/2027.42/154735/Schers\%20Deep\%20Blue\%20article\% 20file.pdf? sequence $=1$ \&isAllowed $=y$.

11 Goodyear-Smith F, Kinder K, Mannie C, et al. Relationship between the perceived strength of countries' primary care system and COVID-19 mortality: an international survey study. BJGP Open 2020;4

12 Pidd H, Garside J. 'We had zero information': GPs in the dark over Covid-19 tests, 2020. The Guardian. Available: https://www. theguardian.com/world/2020/may/06/we-have-had-zero-informationgps-in-the-dark-over-covid-19-tests

13 Huston P, Campbell J, Russell G, et al. COVID-19 and primary care in six countries. BJGP Open 2020;4. doi:10.3399/bjgpopen20X101128. [Epub ahead of print: 27 Oct 2020].

14 Verhoeven V, Tsakitzidis G, Philips H, et al. Impact of the COVID-19 pandemic on the core functions of primary care: will the cure be worse than the disease? A qualitative interview study in Flemish GPs. BMJ Open 2020;10:e039674.

15 Leis JA, Born KB, Theriault G, et al. Using antibiotics wisely for respiratory tract infection in the era of covid-19. BMJ 2020;371:m4125.

16 Ray KN, Shi Z, Gidengil CA, Poon SJ, et al. Antibiotic prescribing during pediatric direct-to-consumer telemedicine visits. Pediatrics 2019;143:e20182491.

17 van de Pol AC, Boeijen JA, Venekamp RP, et al. Impact of the COVID-19 pandemic on antibiotic prescribing for common infections in the Netherlands: a primary care-based observational cohort study. Antibiotics 2021;10. doi:10.3390/antibiotics10020196. [Epub ahead of print: 18 Feb 2021].

18 Pani A, Lauriola M, Romandini A, et al. Macrolides and viral infections: focus on azithromycin in COVID-19 pathology. Int $J$ Antimicrob Agents 2020;56:106053. 